Saleh Alsulamy

Ibrahim Falqi

Mohamed Mansour $\bowtie$

Shaik Dawood

Abdullah Alshehri

https://doi.org/10.21278/TOF.453018320

ISSN 1333-1124

eISSN 1849-1391

\title{
IMPLEMENTING ISO 14001 AND ENVIRONMENTAL PERFORMANCE EVALUATION: A LOGISTIC REGRESSION MODEL
}

\begin{abstract}
Summary
Due to the growing popularity of environmental management systems and the ongoing debate among practitioners and researchers concerning the influence of environmental management systems on environmental performance, there is a need to assess how the implemented environmental management systems impact the environment. The current study examines the relationship between the guidelines provided by the ISO 14031 and ISO 14001 standards from three aspects, namely, utilizing information and data, planning for environmental performance and reviewing and improving environmental performance. This study will utilize a binary logistic regression to model and analyse the link between ISO 14001 and ISO 14031 using a 7-point Likert scale questionnaire. A total of 590 companies operating within the Saudi Arabia industrial sector were invited to take part in the study. The collection of data using questionnaires lasted from January to March 2019, and the results were analysed and compared with those of related studies. The model included a dependent variable representing whether the company is certified or not for ISO 14001 and 13 independent variables representing the main ISO 14031 guidelines. The research findings revealed that the developed model predicts $92.8 \%$ of the values, and the remaining $7.2 \%$ of the values are not covered. Thirteen independent variables were positively correlated with the dependent variable, indicating that the company is certified. The results of this study contribute significantly to the determination of the relationship between environmental performance and ISO 14001 certification.
\end{abstract}

Keywords: binary logistic regression, environmental performance evaluation, environmental management systems, ISO 14031, ISO 14001

\section{Introduction}

Recently, there has been great interest in adopting environmental management systems (EMSs), mainly the international standard ISO 14001, due to their role in enhancing the public image, relationships with stakeholders, and environmental performance (EP) of industrial companies [1-3]. In particular, an increasing number of companies have implemented the standards to manage their EP [4]. By 2018, a total of 317,646 companies in 
Implementing ISO 14001 and

Environmental Performance Evaluation:

A Logistic Regression Model
S. Alsulamy, I. Falqi, M. Mansour

S. Dawood, A. Alshehri

174 different countries were certified according to ISO 14001 [5]. Nonetheless, a common reproach is that the ISO 14001 certification does not measure the company's actual EP [6]. Concurrently, many companies tend to concentrate on implementing environmental management strategies such as environmental performance evaluation (EPE) without the need for implementing an EMS [7, 8]. This raises concerns about how an EMS relates to environmental efficiency in practice. One way of determining the link between the EP and the certification of ISO 14001 is tracing the development of environmental indicators to assess if environmental auditors have achieved an improvement or not. Another approach to assess this relationship is to compare EP of ISO 14001-certified and uncertified companies. For example, Morrow and Rondinelli [9] evaluated how the EMS adoption and certification impacts EP using a case study of five gas and domestic energy companies in Germany. The study findings revealed that the companies that are ISO 14001 certified showed improvements in EP. Despite the positive effect of the ISO 14001 certification, there are also various criticisms, with the most common reproach being that the actual EP is not measured by the certification of ISO 14001[10]. Similarly, Rondinelli and Vastag [11] ascertain that ISO 14001 certification neither measures nor ensures improved EP. The authors also add that ISO 14001 certification does not guarantee regulatory compliance of a certified facility.

A significant number of scholars strive to examine how implementing EMS influences the EP, benefits, and expenses of a company. However, previous research results on the impact of ISO 14001 certification of a company on the EP are still inconsistent. Based on a $49 \%$ response rate out of 354 companies surveyed, Enroth and Zackrisson [12] concluded that the ISO 14001 certification had a positive effect on EP. Senior managers' commitment to an ISO 14001-certified company will have a positive impact by improving the environmental mindfulness of the staff and changing organisational behavior based on the environmental concerns, thus increasing the chances of attaining desired EP [13]. Moreover, studies have brought to light that companies with an ISO 14001-certified EMS have stronger chances of achieving a higher EP $[14,15]$. Aiyub et al. [16] examined EP of 59 companies in the UK that were already ISO 14001 certified. The researchers revealed that the companies improved their procedures and documentation, achieved increased awareness among the staff, improved their reputation, and enhanced their structures following the ISO 14001 certification. The authors further revealed that the standard continued to face problems relating to expenditures and time available during the implementation procedures and upholding the standard. Bansal and Bogner [17] argued that certified companies reduced their electricity, lubricants, and natural gas use while producing lesser amounts of contaminated water and solid waste.

Erauskin-Tolosa et al. [18] showed a positive relationship between corporate EP and the certification of the EU Eco-Management and Audit Scheme (EMAS) after reviewing a total of 53 scholarly studies that analysed 182,926 companies. Melnyk et al. [19] revealed that companies that happen to possess an official EMS such as ISO 14001 consider the EMS impact beyond pollution reduction and consider a significant positive effect on various dimensions of operations performance. Testa et al. [20] hypothesized that implementing an environmental management system within energy-intensive industries impacts the long- and short-term goals of EP. The authors further elucidated that a different impact of EMAS and ISO14001 on EP may occur. Qi et al. [21] investigated how corporate EP is impacted by internalization. The authors concluded that internalization mediates the relationship between the EP and ISO 14001 certification. Heras-Saizarbitoria et al. [22] also examined the impact of the motivation sources that result in companies adopting EMSs, on the systems' outcomes. Their results revealed that companies enjoy more significant device benefits upon the adoption of EMS.

Some studies document that the ISO 14001 adoption negatively affects EP. On the other hand, other studies have not established a link between ISO 4001 implementation and EPE. 
Ammenberg [23] examined if EMS improved EP carrying out a case study of 26 small enterprises from various fields. The author hypothesized that an ISO 14001 certification does not guarantee improved EP, although it could result in a reduction in environmental pollution. Welch et al. [24] explored the impact of ISO 14001 and EMAS on business development and EP. The authors established some positive impacts of ISO 14001 and EMAS on the aspects of $\mathrm{EP}$, while there were neither effects nor adverse effects on the EP parameters. These findings were consistent with those of Ammenberg [10]. Zobel [25] examined changes in the performance of 115 Swedish manufacturing companies from 6 different environmental sectors for a period of 12 years. Among these companies, some implemented EMS while others had not. The authors established that there existed no statistically significant relationship between a change in EPE and ISO 14001 certification. Aravind and Christmann [26] argued that ISO 14001 certified companies may not have implemented standard requirements sufficiently and the quality of the implementation standard impacted the EP of the facilities. The authors further revealed that the EP of the uncertified and certified companies was not substantially different from the low-quality implementers and the overall sample, whereas high-quality implementers performed better compared to their uncertified counterparts. Barla [27] showed how the ISO 14001 implementation could have unclear effects on environmental management results and practices. Heras-Saizarbitoria et al. [28] also investigated financial projections of the ISO 14001 certification in Spain. The authors did not establish any evidence to show that the ISO 14001 certification resulted in improved performance.

Consequently, a general inference cannot be made as to whether EMSs have beneficial impacts on corporate EP. Additionally, while measuring the EP of industry projects, MEPI [29] revealed that there is no statistically significant relationship between EP and EMS certification. The researcher included six industrial sectors of six EU nations. Montabon et al. [14] concluded that some of the companies that were EMS certified performed even worse than those that were not EMS certified. However, the research did not measure the rate at which EP changes between EMS non-certified and EMS certified. The primary goal of the National Database on Environmental Management System of the Environmental Law Institute and the University of North Carolina in the Chapel Hill NDEMS [30] was to examine how ISO 14001 certification impacts a company's environmental and economic performance. The project is yet to arrive at some conclusions concerning how EMS impacts EP. Moreover, although some scholars have reported a lack of relationship between EP and ISO 14001 [31], there is still no agreement between researchers concerning the definition of EPE [32] and the interrelationship between EPE and adopting an EMS. As such, examining how EMS influences the EPE of a company and vice versa remains a subject of considerable interest among scholars and researchers.

The current study examines the relationship between EPE and ISO 14001 certification using a case study of companies that were ISO 14001 certified by 2018. The companies of interest are those located in Saudi Arabia. A questionnaire was used for data collection. Due to the representation of the dependent $(Y)$ and independent variables in the current study being binary, 1 shows that the company is ISO 14001 certified and 0 indicates that the company is not certified. It is, therefore, appropriate to use one of the regression models for modelling this situation. In this context, we have established that the Binary Logistic Regression (BLR) is the most common; hence, it was chosen as the modelling approach in this study. The model computes odds ratios $(O R s)$ for one response compared to the other odds to support the decision-making process [33].

The main goal of this study was to generate a regression model that relates to the EPE guidelines defined within the ISO 14031 standard for implementing the international ISO 14001 standard and EMS. The following research question guided the study: Do the ISO 14031 guidelines for EPE significantly predict the ISO 14001 certification status of industrial 
companies? The null hypothesis was that there exists no statistically significant relationship between EPE and ISO 14001 certification. Contrary, the alternative hypothesis was that there is a statistically significant relationship between EPE and ISO 14001 certification. The statistical analysis is based on a two-tail test and a level of significance $(\alpha)$ equal to 0.05 . To answer the research question, the preceding section describes the methodological approach adopted in this study. The interactions among independent variables were neglected in the current study.

The remaining four sections of this paper present the following. The adopted materials and methods are illustrated in Section 2. Section 3, which covers the results, utilizes the solution methodology to assess the developed BLR model's accuracy built upon the judgment and the opinions of industrial specialists. Section 4 includes a discussion of the results. Lastly, section 5 provides a comprehensive summary of the research.

\section{Materials and methods}

A qualitative design was selected since this paper is concerned with experiences with ISO 14001 and ISO 14031. The study employed a BLR to analyse the gathered binary data [34]. Comprehensive advantages and disadvantages of BLR with other classification methods are discussed in [35]. To examine the relationship between the variables, Cohen's standard was utilized [36]. Besides, Holm correlations were used to examine the correlations [37]. For ordinal data, the researcher used the $\mathrm{R}$ language to analyse and describe the collected data [38]. The reference level of the variables was set as equal to 0 . The collinearity check was done using variance inflation factor (VIF) values [39]. The overall model fit was measured based on the values of $\chi^{2}$ and McFadden $R^{2}$. The model coefficient calculations were carried according to the Omnibus likelihood ratio test, and the confidence intervals were estimated based on the ORs for a 95\% interval [39].

Companies in the Saudi Arabian industrial sector were selected for data collection due to the efforts of Saudi companies to achieve ISO 14001 certification and to understand the importance of working with environmental laws [40]. The Saudi industrial sector includes more than 30 industrial fields, such as construction, agriculture, fishing, etc. According to a survey of certifications conducted by ISO for management system standards, the total number of certified companies in Saudi Arabia is 362, distributed among 31 industrial fields in 497 sites $[5,41]$. The collection of data using a questionnaire was ideal since quantitative research permits a greater degree of flexibility in terms of sources of data [42]. Also, the questionnaire was an ideal tool for collecting data since participants had sufficient time to think and respond. Further, the questionnaire was able to cover an extensive geographic area as compared with other survey techniques. The questionnaire was designed to examine the answers provided by company managers at two different levels: top managers and executive managers.

In this study, a random sample consisting of 900 companies was generated, representing industrial fields and company details, to identify the sample size. The set of candidate companies included certified and uncertified companies from all industrial fields. An email was sent to the managers of candidate companies between January and March 2019. The filled-out questionnaires were received, collected, and prepared for processing using the RapidMiner software [43]. Data cleansing was done by removing low-quality, duplicate, incomplete, and highly correlated records [44]. For validity purposes, a feedback call for a set of 150 companies was done to ensure that the collected data had the required accuracy. In total, 596 questionnaires out of the 900 received were found to be complete and appropriate for statistical analysis. The valid set included 235 certified and 361 uncertified companies and covered 30 industrial fields, as shown in Table 1. The table presents data on the type of industrial sector and the number of certified and uncertified companies that responded and 
sent a correctly filled out questionnaire. Table 1 shows that the largest sector participating in the study was construction, with 46 certified and 60 uncertified companies, from a total of 106 out of 596 companies. Moreover, the sample consists of 9\% small-sized, 31\% mediumsized, and $60 \%$ large-sized enterprises based on the Organisation for Economic Co-operation and Development's Working Body for small and medium-sized enterprises and the European Commission DG XXIII classification for business enterprises about the total number of employees. In a micro-sized enterprise, the employee number ranges from 1 to 9 , in a smallsized enterprise the employee number ranges from 10 to 99, in a medium-sized enterprise the employee number ranges from 100 to 499, and in a large-sized enterprise the employee number is more than 500 .

To scale EPEs in the Saudi industry, ISO 14031 was utilized. A questionnaire that was scaled as either 0 or 1 , as listed in [3], was developed based on the requirements of the ISO 14031 standard and emailed to the selected companies. The questionnaire constructs comprised 13 items characterized by three descriptor variables: utilizing information and data, planning for EPEs and reviewing and improving EPEs [45]. Additionally, there was a question that examined whether the company was ISO 14001 certified or not, which represented the value of the predicted variable $(Y)$. Variable $(Y)$ was coded as a binary variable, with 0 indicating that the company was not certified and 1 indicating that it was ISO 14001 certified. The descriptor variables included items 5, 6, and 2, respectively. The items belonging to the first measurement were coded as "P1" to "P5". The items belonging to the second measurement were coded as "D1" to "D6". Lastly, items belonging to the third measurement were coded as "R1" and "I1". The respondents ranked the constructs of the ISO 14031 implementation level on a " $0-1$ " scale, where the rating of 1 indicated strong agreement with the statement. This approach showed the respondents' views and opinions on the degree of implementation in their company [46, 47].

Table 1 Response rates of certified and uncertified companies and their industrial fields

\begin{tabular}{|c|c|c|c|c|c|c|c|}
\hline \multirow{2}{*}{$\begin{array}{l}\text { Sr. } \\
\text { No. }\end{array}$} & \multirow[t]{2}{*}{ Industrial sector } & \multicolumn{4}{|c|}{$\begin{array}{l}\text { \# of certified \# of uncertified } \\
\text { companies companies }\end{array}$} & \multicolumn{2}{|c|}{ Total } \\
\hline & & $n$ & $\%$ & $n$ & $\%$ & $n$ & $\%$ \\
\hline 1 & Agriculture, fishing, and forestry & 1 & 0.43 & 3 & 0.83 & 4 & 0.67 \\
\hline 2 & Basic metal and fabricated metal products & 20 & 8.51 & 30 & 8.31 & 50 & 8.39 \\
\hline 3 & Chemicals, chemical products, and fibres & 11 & 4.68 & 20 & 5.54 & 31 & 5.20 \\
\hline 4 & Concrete, cement, lime, plaster, etc. & 6 & 2.55 & 10 & 2.77 & 16 & 2.68 \\
\hline 5 & Construction & 46 & 19.57 & 60 & 16.62 & 106 & 17.79 \\
\hline 6 & Education & 2 & 0.85 & 8 & 2.22 & 10 & 1.68 \\
\hline 7 & Electrical and optical equipment & 7 & 2.98 & 8 & 2.22 & 15 & 2.52 \\
\hline 8 & Electricity supply & 2 & 0.85 & 4 & 1.11 & 6 & 1.01 \\
\hline 9 & Engineering services & 25 & 10.64 & 35 & 9.70 & 60 & 10.07 \\
\hline 10 & Financial intermediation, real estate, and renting & 5 & 2.13 & 10 & 2.77 & 15 & 2.52 \\
\hline 11 & Food products, beverage, and tobacco & 13 & 5.53 & 18 & 4.99 & 31 & 5.20 \\
\hline 12 & Health and social work & 1 & 0.43 & 5 & 1.39 & 6 & 1.01 \\
\hline 13 & Hotels and restaurants & 1 & 0.43 & 3 & 0.83 & 4 & 0.67 \\
\hline 14 & Information technology & 2 & 0.85 & 5 & 1.39 & 7 & 1.17 \\
\hline 15 & Machinery and equipment & 9 & 3.83 & 15 & 4.16 & 24 & 4.03 \\
\hline 16 & Manufacture of coke and refined fuel products & 7 & 2.98 & 8 & 2.22 & 15 & 2.52 \\
\hline 17 & Manufacture of wood and wood products & 1 & 0.43 & 5 & 1.39 & 6 & 1.01 \\
\hline
\end{tabular}




\begin{tabular}{|c|c|c|c|c|c|c|c|}
\hline \multirow{2}{*}{$\begin{array}{l}\text { Sr. } \\
\text { No. }\end{array}$} & \multirow[t]{2}{*}{ Industrial sector } & \multicolumn{4}{|c|}{$\begin{array}{l}\text { \# of certified \# of uncertified } \\
\text { companies companies }\end{array}$} & \multicolumn{2}{|c|}{ Total } \\
\hline & & $n$ & $\%$ & $n$ & $\%$ & $n$ & $\%$ \\
\hline 18 & Non-metallic mineral products & 2 & 0.85 & 3 & 0.83 & 5 & 0.84 \\
\hline 19 & Other services & 2 & 0.85 & 4 & 1.11 & 6 & 1.01 \\
\hline 20 & Other social services & 1 & 0.43 & 5 & 1.39 & 6 & 1.01 \\
\hline 21 & Pharmaceuticals & 1 & 0.43 & 3 & 0.83 & 4 & 0.67 \\
\hline 22 & Printing companies & 1 & 0.43 & 5 & 1.39 & 6 & 1.01 \\
\hline 23 & Public administration & 9 & 3.83 & 15 & 4.16 & 24 & 4.03 \\
\hline 24 & Pulp, paper, and paper products & 1 & 0.43 & 5 & 1.39 & 6 & 1.01 \\
\hline 25 & Recycling & 15 & 6.38 & 20 & 5.54 & 35 & 5.87 \\
\hline 26 & Rubber and plastic products & 4 & 1.70 & 8 & 2.22 & 12 & 2.01 \\
\hline 27 & Textiles and textile products & 6 & 2.55 & 10 & 2.77 & 16 & 2.68 \\
\hline 28 & Transport, storage, and communication & 5 & 2.13 & 8 & 2.22 & 13 & 2.18 \\
\hline 29 & Water supply & 17 & 7.23 & 17 & 4.71 & 34 & 5.70 \\
\hline 30 & $\begin{array}{l}\text { Wholesale and retail trade, repairs of motor } \\
\text { vehicles, motorcycles and personal and household } \\
\text { goods }\end{array}$ & 2 & 0.85 & 4 & 1.11 & 6 & 1.01 \\
\hline & Total & 235 & 100 & 361 & 100 & 596 & 100 \\
\hline
\end{tabular}

\section{Results}

The collected data were formulated as a BLR model with one dependent variable and 13 independent variables. The $t$ response variable $(Y)$ represents the status of the company regarding ISO 14001 certification. It takes the level of 1 when the company is ISO 14001certified and the level of 0 if the company is not certified. The explanatory variables represent the guidelines outlined in ISO 14031 (see the measuring tool given in [3]). The model was developed and evaluated based on an $\alpha$ of 0.05 in terms of fit measures, model coefficients, and predictive measures.

\subsection{Assumption check}

The result of Kendall's tau $B$ correlation analysis depicted in Table 2 showed that there was not a statistically significant correlation among the model's independent variables at $p<.05$. The relationship was positive, weak and not reaching the level of statistical significance. From the research findings, the researcher failed to reject the null hypothesis and concluded that the variables under investigation were positively correlated. The researcher performed a BLR to assess whether the explanatory variables had a significant impact on the likelihood of observing the $Y$ classification of the ISO 14001-certified company. The reference classification for $Y$ was 0 . A total number of 596 companies were included in this analysis: 235 in the ISO 14001-certified company category and 361 in the ISO 14001-uncertified company category. Table 3 presents the multicollinearity check in terms of VIFs for each predictor in the model and tolerance. The table indicates that the VIF values are below 5, which indicated that there was no multicollinearity in the model [48]. The constant-only model was tested and it was significant: $\operatorname{Wald}(1)=26.23, p<0.001$. This model classified all cases as working, which correctly classified $60.6 \%$ of the data by chance. 
Table 2 Kendall's Tau $B$ - correlation matrix

\begin{tabular}{|c|c|c|c|c|c|c|c|c|c|c|c|c|}
\hline P1 & $\mathrm{P} 2$ & P3 & P4 & P5 & D1 & D2 & D3 & D4 & D5 & D6 & R1 & I1 \\
\hline $\mathrm{P} 1-$ & $0.23^{* * *}$ & $0.29^{* * *}$ & $0.24^{* * *}$ & $0.32^{* * *}$ & $0.26^{* * *}$ & $0.19^{* * *}$ & $0.26^{* * *}$ & $0.17^{* * *}$ & $0.18^{* * *}$ & $0.26^{* * *}$ & $0.29^{* * *}$ & $0.29^{* * *}$ \\
\hline P2 & - & $0.14^{* * *}$ & $0.10^{* *}$ & $0.24^{* * *}$ & $0.16^{* * *}$ & $0.27^{* * *}$ & $0.27^{* * *}$ & $0.21^{* * *}$ & $0.26^{* * *}$ & $0.17^{* * *}$ & $0.32^{* * *}$ & $0.16^{* * *}$ \\
\hline P3 & & - & $0.10^{*}$ & $0.23^{* * *}$ & $0.17^{* * *}$ & $0.20^{* * *}$ & $0.27^{* * *}$ & $0.29^{* * *}$ & $0.18^{* * *}$ & $0.24^{* * *}$ & $0.18^{* * *}$ & $0.31^{* * *}$ \\
\hline P4 & & & - & $0.28^{* * *}$ & $0.18^{* * *}$ & $0.22^{* * *}$ & $0.15^{* * *}$ & $0.27^{* * *}$ & $0.26^{* * *}$ & $0.25^{* * *}$ & $0.10^{*}$ & $0.15^{* * *}$ \\
\hline P5 & & & & - & $0.21^{* * *}$ & $0.35^{* * *}$ & $0.32^{* * *}$ & $0.30^{* * *}$ & $0.28^{* * *}$ & $0.34^{* * *}$ & $0.19^{* * *}$ & $0.25^{* * *}$ \\
\hline D1 & & & & & - & $0.28^{* * *}$ & $0.29^{* * *}$ & $0.28^{* * *}$ & $0.17^{* * *}$ & $0.17^{* * *}$ & $0.25^{* * *}$ & $0.31^{* * *}$ \\
\hline D2 & & & & & & - & $0.31^{* * *}$ & $0.25^{* * *}$ & $0.23^{* * *}$ & $0.27^{* * *}$ & $0.10^{* * *}$ & $0.32^{* * *}$ \\
\hline D3 & & & & & & & - & $0.18^{* * *}$ & $0.24^{* * *}$ & $0.34^{* * *}$ & $0.20^{* * *}$ & $0.28^{* * *}$ \\
\hline D4 & & & & & & & & - & $0.10^{* * *}$ & $0.21^{* * *}$ & $0.12^{* *}$ & $0.31^{* * *}$ \\
\hline D5 & & & & & & & & & - & $0.28^{* * *}$ & $0.15^{* * *}$ & $0.18^{* * *}$ \\
\hline D6 & & & & & & & & & & - & $0.15^{* * *}$ & $0.24^{* * *}$ \\
\hline $\mathrm{R} 1$ & & & & & & & & & & & - & $0.13^{* *}$ \\
\hline I1 & & & & & & & & & & & & - \\
\hline
\end{tabular}

Note: $* \mathrm{p}<.05, * * \mathrm{p}<.01, * * * \mathrm{p}<.001$

Table 3 Model assumption checks: VIFs for independent variables

\begin{tabular}{|cccccccccccccc|}
\hline Variable & P1 & P2 & P3 & P4 & P5 & D1 & D2 & D3 & D4 & D5 & D6 & R1 & I1 \\
\hline VIF & 1.17 & 1.35 & 1.34 & 1.27 & 1.38 & 1.23 & 1.14 & 1.2 & 1.24 & 1.15 & 1.2 & 1.4 & 1.18 \\
Tolerance & 0.85 & 0.74 & 0.75 & 0.79 & 0.73 & 0.82 & 0.87 & 0.84 & 0.81 & 0.87 & 0.83 & 0.7 & 0.85 \\
\hline
\end{tabular}

\subsection{Model fit}

The significance level $(\alpha)$ of 0.05 was used to evaluate the model. The overall model was significant, $\chi 2(13)=606, p<0.001$, which suggested that the explanatory variables of the model significantly impacted the odds of observing an ISO 14001-certified company category of $\mathrm{Y}$. To determine the model fit, McFadden's R-squared $\left(\mathrm{R}^{2} \mathrm{McF}\right)$, Cox and Snell's R-squared $\left(\mathrm{R}^{2} \mathrm{CS}\right)$, and Nagelkerke's R-squared $\left(\mathrm{R}^{2} \mathrm{~N}\right)$ values were calculated, where the values greater than 0.2 indicated the model had an excellent fit [49]. The $\mathrm{R}^{2} \mathrm{McF}, \mathrm{R}^{2} \mathrm{CS}$, and $\mathrm{R}^{2} \mathrm{~N}$ values calculated for this model were $0.76,0.63$, and 0.86 , respectively, and $\chi 2$ was equal to 606 with a degree of freedom (df) equal to 13 and a $p<0.001$, as depicted in Table 4 . The table shows the $\chi 2$, df, and $p$-values for independent variables. The Omnibus likelihood ratio tests shown in Table 5 indicate the significance of the model coefficients. The $p$-values are $<0.05$. The calculation of the $p$-values, $\chi 2$, and $\mathrm{df}$ aimed to define each of the independent variable's significance, as presented in Table 6 . The table shows that the 13 variables are significant, with $d f_{s}$ equal to 1 and $p$-values less than 0.001 . Since the $p$-values are $<0.05$ (Table 6), it is important to incorporate the variables in the model. As such, one would not need to eliminate any variables from the model.

Table 4 Model fit measures and pseudo R2

\begin{tabular}{|ccccccc|}
\hline \multirow{2}{*}{ Model } & \multicolumn{3}{c}{ Pseudo R2 } & \multicolumn{3}{c|}{ Overall model test } \\
\cline { 2 - 7 } & $\boldsymbol{R}_{\boldsymbol{M c F}}^{2}$ & $\boldsymbol{R}_{\boldsymbol{C S}}^{2}$ & $\boldsymbol{R}_{N}{ }_{N}$ & $\chi^{2}$ & df & $\boldsymbol{p}$ \\
\hline 1 & 0.76 & 0.63 & 0.86 & 606 & 13 & $<0.001$ \\
\hline
\end{tabular}


Implementing ISO 14001 and

Environmental Performance Evaluation:

A Logistic Regression Model
S. Alsulamy, I. Falqi, M. Mansour S. Dawood, A. Alshehri

Table 5 Model coefficients: Omnibus likelihood ratio tests

\begin{tabular}{|c|c|c|c|c|c|c|c|c|c|c|c|c|}
\hline Predictor & P1 & P2 & P3 & P4 & P5 & D1 & D2 & D3 & D4 D5 & D6 & R1 & I1 \\
\hline$\chi^{2}$ & 30.34 & 26.86 & 21.2 & 16.85 & 35.56 & 14.69 & 16.66 & 11.65 & & 15.46 & 37.73 & 27.66 \\
\hline
\end{tabular}

Table 6 presents the unstandardized regression weight $(B)$, the degree to which the unstandardized regression weight can vary by $B$, standard error (SE), the $95 \%$ confidence interval $(C I)$ for $O R s(95 \% C I)$, Wald $\chi^{2}, p$, and $O R$ for independent variables. The "P1" coefficient was significant, $B=2.04, O R=7.72, p<0.001$, signifying that if "P1" increases by one unit the odds of observing the ISO 14001-certified company category of $Y$ increase by nearly $672 \%$. The regression coefficient for "D1" was significant, $B=1.49, O R=4.46$, $p<0.001$, signifying that if "D1" increases by one unit, the odds of observing the ISO 14001certified company category of $Y$ increase by nearly $346 \%$. The regression coefficient for "I1" was significant, $B .1 .98, O R=7.26, p<0.001$, signifying that if "I1" increases by one unit, the odds of observing the ISO 14001-certified company category of $Y$ increase by nearly $626 \%$.

Table 6 Logistic model coefficients with P1, P4, D2, D5, I1, P2, P5, D3, D6, P3, D1, D4, and R1 predicting $Y$

\begin{tabular}{|ccccccc|}
\hline Variable & $B$ & $S E$ & $95.0 \% C I$ & $\chi^{2}$ & $p$ & $O R$ \\
\hline (Intercept) & -11.45 & 1.19 & {$[-13.77,-9.12]$} & 92.90 & $<0.001$ & \\
P1 & 2.04 & 0.40 & {$[1.26,2.83]$} & 26.02 & $<0.001$ & 7.72 \\
P2 & 2.05 & 0.43 & {$[1.21,2.89]$} & 22.82 & $<0.001$ & 7.74 \\
P3 & 1.83 & 0.43 & {$[0.99,2.66]$} & 18.29 & $<0.001$ & 6.21 \\
P4 & 1.62 & 0.42 & {$[0.80,2.44]$} & 15.07 & $<0.001$ & 5.06 \\
P5 & 2.32 & 0.43 & {$[1.47,3.17]$} & 28.52 & $<0.001$ & 10.13 \\
D1 & 1.49 & 0.41 & {$[0.69,2.29]$} & 13.41 & $<0.001$ & 4.46 \\
D2 & 1.55 & 0.39 & {$[0.77,2.32]$} & 15.36 & $<0.001$ & 4.70 \\
D3 & 1.34 & 0.41 & {$[0.54,2.14]$} & 10.79 & 0.001 & 3.82 \\
D4 & 1.21 & 0.41 & {$[0.41,2.02]$} & 8.74 & 0.003 & 3.36 \\
D5 & 1.16 & 0.40 & {$[0.38,1.94]$} & 8.50 & 0.004 & 3.18 \\
D6 & 1.53 & 0.41 & {$[0.73,2.32]$} & 14.22 & $<0.001$ & 4.62 \\
R1 & 2.42 & 0.44 & {$[1.56,3.28]$} & 30.39 & $<0.001$ & 11.23 \\
I1 & 1.98 & 0.41 & {$[1.19,2.78]$} & 23.91 & $<0.001$ & 7.26 \\
\hline
\end{tabular}

Estimates represent the $\log$ odds of " $Y=1$ " vs. " $Y=0$ ".

Table 7 Model predictive measures: Classification table, $Y$

\begin{tabular}{|cccc|}
\hline \multirow{2}{*}{ Observed } & \multicolumn{2}{c|}{ Predicted } & \multirow{2}{*}{$\%$ Correct } \\
\cline { 2 - 3 } & $Y=0$ & $Y=1$ & \\
\hline ISO 14001-uncertified company, $Y=0$ & 340 & 21 & 94.2 \\
ISO 14001-certified company, $Y=1$ & 22 & 213 & 90.6 \\
\hline
\end{tabular}

The cut-off value is set to 0.5 .

According to the percentage of the explained deviation, the most appropriate logit model expression is defined in Equations (1) and (2). These equations depict the results of the fitted BLR model to show the relationship between the dependent variable $(Y)$ and the 13 explanatory variables extracted from ISO 14031. The equation of the fitted model is as follows:

$$
Y=\frac{\exp (\text { eta })}{(1+\exp (\text { eta }))}
$$

where $Y$ represents the probability of event 1, i.e., the company has an ISO 14001 certification and the linear function of eta is equal to: 


$$
\begin{aligned}
\text { eta }= & -11.45+2.04 \cdot P 1+2.05 \cdot P 2+1.83 \cdot P 3+1.62 \cdot P 4+2.32 \cdot P 5+1.49 \cdot D 1+ \\
& +1.55 \cdot D 2+1.34 \cdot D 3+1.21 \cdot D 4+1.16 \cdot D 5+1.53 \cdot D 6+2.42 \cdot R 1+1.98 \cdot I 1
\end{aligned}
$$

The logit model utilizing the 13 independent variables was also applicable for assessing EP for industrial companies, irrespective of whether they have ISO 14001 certification, by deciding the values of the binary variables. For instance, if the values of the 13 independent variables from P1 to I1 are $(1,1,1,0,1,1,1,1,1,1,1,0,1)$, then the eta values are equal to 7.05 and $Y$ to 1.00 . This value shows that the probability is 1.00 that the company is ISO 14001 certified. On the contrary, values of $(0,0,0,1,0,1,0,1,0,1,0,1,0)$ correspond to eta equals -3.41 and $Y$ equals 0.03 . This value signifies that the probability that the company is ISO 14001 certified is equivalent to 0.03 .

\section{Discussion}

BLR modelling was utilized to prove a statistically significant relationship between industrial companies' ISO 14001 certification status and ISO 14031 guidelines for the EPE. Besides, the findings revealed that none of the guidelines that were represented by the explanatory variables could be removed from the model. Thus, the observed heterogeneity in prior studies concerned with an evaluation of the relationship was explained by using different measurement tools, performance indicators, and industrial categories. Additionally, the 13 indicators of EP as outlined in ISO 14031 were ranked per their impact on the ISO 14001 certification status based on the values of the correlation coefficients.

The findings of this study agree with those of other scholars who have identified a statistically significant relationship between EPE and the implementation of ISO 14001. Such scholars include $[4,8,12-24]$ and they disagree with the voices calling for negative effects, such as in $[9,12,25-29,31,32,37,45,50]$. Additionally, this study demonstrates that there is a relationship, which rejects the claim of MEPI [29] that there does not exist any statistically significant relationship between EPE and the implementation of EMS. The fact that we found a relationship between EPE and the company's status in terms of being environmentally certified or not according to one of the international EMS requirements indicates that the existence of such a relationship may be useful in the application of ISO 14031 as a requirement for obtaining ISO 14001 or other EMSs, in addition to setting technical EPE criteria for different economic activities.

The adopted BLR approach suggests a positive relationship among EPE indicators and ISO 14001 requirements, allowing practitioners to direct their engineering attention and focus on reviewing and improving EPE, planning for EPE, and using data and information based on the average coefficient performance of the independent variables of each dimension. Additionally, the model estimates high positive regression coefficients for four variables, ranging from 2.04 to 2.42: Periodical EPE reviews (R1), the data on the selection and use of environmental indicator is a useful form (P5), EPE planning based on the interested parties' views and EP criteria (P2), and the EPE planning based on the controlling/significant environmental indicators (P1). The relevance of these variables shows the need to design and plan ways of improving the indicator value of the environmental condition. This reflects the importance of EMS implementation on the EP of industrial companies. As the environmental management research moves from observational studies and environmental impact assessment design to directly test the contribution of companies to environmental pollution, there is a growing need to develop and transition to a modernized set of tools, such as sustainable EMSs, new environmental protection technologies, the development of new EPE models, and the inclusion of environmental regulations in the design process of products and industrial systems. 
This research represents a scientific basis for judging the relationship between EPE or ISO 14031 guidelines and the implementation of EMSs such as ISO 14031, EMAS, or any other international standard compared to other techniques that depend mainly on descriptive statistics measures. This approach satisfies the decision-making process to a certain level of significance. It opens research directions to explore environmental management measures and to direct technical measures or indicators. The type of industry can be included in the proposed model as a single independent variable as well as the type of respondent and other controlling variables. These features suggest that our overall approach could be used by many investigators because the independent variables of the model apply to all industrial companies regardless of their size and industrial specialization category.

Although identifying a BLR model represents an extraordinary step in investigating the relationship between EPE and EMS ISO 14001, much additional work needs to be done. For instance, in the current study, the model assumed the interactions between the explanatory variables. Therefore, a further study needs to be conducted to examine the relationship between explanatory variables. Additionally, the model only focused on general ISO 14031 guidelines that relate to operational, management and general indicators of the environmental conditions. As such, a further study is needed to include specific technical and engineering environmental indicators as part of the environmental condition indicators. Moreover, limitations include evaluating only EPE for Saudi industrial companies; increasing the sample size could have beneficial effects on the model results. Furthermore, the estimates of the model coefficients are based on the environmental managers' views and opinions; thus, they are subject to confounding and bias, which may have also impacted the estimated values of the model. The study investigates the relationship between EPE and ISO 14001 and it is concluded that EPE depends on various variables, both of which are exogenous and endogenous, rather than EMS and ISO 14001 certification. Indeed, the economic performance may lead to some latent variables working as drivers influencing EPE. So, a possibility always remains that certified firms have EPE which is different in other ways. However, the used methods determine the direct effect of the ISO 14001 certification on EPE. A limitation also exists as there is no distinction made between the companies that received an ISO 14001 certification in 2018 and those which had been certified for a longer period. It is believed that the relationship could vary based on the point in time the company was ISO 14001 certified.

Our approach has implications for modelling because it represents the EPE construct in general. Each measurement variable can include another detailed sub-variable. Increasing the level of the variable detail may change the results of the study. The research methodology can be implemented by companies to define the gap between the actual EPEs of their businesses. The independent variables, which are EPE activities, are examined based on the guidelines outlined in the ISO 14031 model [45]. The findings of this study will be greatly beneficial to industry and society at large. Companies will benefit by improving their comprehension of how implementing the guidelines defined by the ISO 14031 standards influences the ISO 14001 certification. These companies will utilise this information for their development and as a marketing tool. Moreover, environmental authorities and customers will find it easier to evaluate the EMSs of companies. Also, the following benefits are available to all companies that will utilize the developed model: The measurement of how far the company's EMS is from its ISO 14001 certification enables the company to concentrate on improving the most effective factors that influence EPE the most by determining coefficients of the model, and it also enables practitioners who work in the field of environmental planning to add new variables to the measurement variables of the developed model. 


\section{Conclusions}

This research belongs to studies that have comprehensively examined the relationship between the implementation of ISO 14031 guidelines and EMS ISO 14001 standard. The primary contribution of this research was the development of a BLR model that can be utilized to define whether there is a relationship between the two variables, which has not been well defined in the existing literature up to date. The developed model includes a binary dependent variable and 13 binary independent variables. The regressor variable represents a company's status in terms of the ISO 14001 implementation. The independent variables represent the guidelines for measuring EP in three areas: planning and preparation for EPE, utilizing the collected data and information and reviewing and improving EPE. The developed BLR model predicts $92.8 \%$ of the values, and the remaining $7.2 \%$ of the values are not covered. Each of the 13 independent variables has a positive coefficient of correlation, implying that the higher the corresponding value of the explanatory variable, the higher the value of the dependent variable and the closer it is to the value (1); thus, the company is certified. The most effective factor influencing the status of a company is a periodic review with a coefficient of 2.42, using environmental condition indicator data with a coefficient of 2.32, EP criteria and the planning of the interested party with a coefficient of 2.05, planning based on the control or significant environmental aspects with a coefficient of 2.04, environmental review contributing to environmental conditions improvement with a coefficient of 1.98, management performance indicator data selection and use with a coefficient of 1.83, operational performance indicator data selection and use with a coefficient of 1.62, systematic and regular environmental planning data collection with a coefficient of 1.55 , documenting environmental reports with a coefficient of 1.53 , the availability of documented EPE procedures with a coefficient of 1.49, analysing EPE data with a coefficient of 1.34, EPE benchmarking with a coefficient of 1.21, and then timely communication of the EP information of the company with a coefficient of 1.16.

The developed BLR model was verified with respect to collinearity using the VIF and the tolerance value. The model fit measures are deviance, overall model fit, $R_{M c F}^{2}, R_{C S}^{2}, R_{N}^{2}$, and $\chi^{2}$. The model coefficients were tested with respect to the Omnibus test, and 95\% confidence interval for ORs. The predictive measures of the model were verified using the classification table. A natural expansion of this study is to use other prediction and classification statistical techniques such as Cox regression, multi-discriminate analysis models and multinomial logistic regression models. Additionally, artificial intelligence models, including gene expression and neural network programming methods, may be potential tools to discover the relationship between the two standards. Industrial companies can utilize the developed logistic regression model as a valuable tool for measuring whether the companies themselves evaluate EP according to ISO 14031, even if they do not implement ISO 14001.

\section{Acknowledgments}

We thank the anonymous reviewers for their comments and suggestions. This study was financially supported by King Khalid University [grant number R.G.P.1/220/41].

\section{Conflict of interest}

The authors declare that there is no conflict of interest.

\section{REFERENCES}

[1] G. Carruthers and F. Vanclay, "The intrinsic features of environmental management systems that facilitate adoption and encourage innovation in primary industries," Journal of Environmental Management, vol. 110, pp. 125-134, 2012/11/15/ 2012. https://doi.org/10.1016/j.jenvman.2012.06.003 
Implementing ISO 14001 and

Environmental Performance Evaluation:

A Logistic Regression Model
S. Alsulamy, I. Falqi, M. Mansour

S. Dawood, A. Alshehri

[2] I. Falqi, S. Alsulamy, and M. Mansour, "Environmental Performance Evaluation and Analysis Using ISO 14031 Guidelines in Construction Sector Industries," Sustainability, vol. 12, no. 5, p. 1774, 2020/02/27 2020. https://doi.org/10.3390/su12051774

[3] M. Mansour and S. Alsulamy, "Evaluating association between implementation of iso 14031 guidelines and iso 14001 certification by industrial sector in saudi arabia," Journal of Environmental Engineering and Landscape Management, vol. 29, no. 1, pp. 61-71, 2021/04/07 2021. https://doi.org/10.3846/jeelm.2021.14123

[4] F. Daily Bonnie, "Achieving sustainability through attention to human resource factors in environmental management," International Journal of Operations \& Production Management, vol. 21, no. 12, pp. 15391552, 2001. https://doi.org/10.1108/01443570110410892

[5] ISO_Survey. (2018, 20 Jan. 2019). ISO survey 2018 results - number of certificates and sites per country and the number of sector overall [Survey]. Available: https://isotc.iso.org/. https://doi.org/10.1787/805541070646

[6] J. Ammenberg, O. Hjelm, and P. Quotes, "The connection between environmental management systems and continual environmental performance improvements," Corporate Environmental Strategy, vol. 9, no. 2, pp. 183-192, 2002/05/01/ 2002. https://doi.org/10.1016/s1066-7938(02)00011-8

[7] J. Hertin, F. Berkhout, M. Wagner, and D. Tyteca, "Are EMS environmentally effective? The link between environmental management systems and environmental performance in European companies," Journal of Environmental Planning and Management, vol. 51, no. 2, pp. 259-283, 2008/03/01 2008. https://doi.org/10.1080/09640560701865040

[8] A. Massoud Jacob, "Perceptions of environmental management systems: an examination of the Mexican manufacturing sector," Industrial Management \& Data Systems, vol. 111, no. 1, pp. 5-19, 2011. https://doi.org/10.1108/02635571111099703

[9] D. Morrow and D. Rondinelli, "Adopting corporate environmental management systems: Motivations and results of ISO 14001 and EMAS certification," European Management Journal, vol. 20, no. 2, pp. 159171, 2002/04/01/ 2002. https://doi.org/10.1016/s0263-2373(02)00026-9

[10] J. Ammenberg, "Do standardised environmental management systems lead to reduced environmental impacts?," Doctoral thesis, comprehensive summary, Linköping Studies in Science and Technology. Dissertations, Linköpings universitet, Linköping, 851, 2003.

[11] D. Rondinelli and G. Vastag, "Panacea, common sense, or just a label?: The value of ISO 14001 environmental management systems," European Management Journal, vol. 18, no. 5, pp. 499-510, 2000/10/01/ 2000. https://doi.org/10.1016/s0263-2373(00)00039-6

[12] M. Enroth and M. Zackrisson, "Environmental management systems -paper tiger or powerful tool," presented at the 2000 Eco-Management and Auditing Conference. June 2000. University of Manchester. UK, 2000, 2000. Available: http://urn.kb.se/resolve?urn=urn:nbn:se:kth:diva-25883

[13] S. M. Savely, A. I. Carson, and G. L. Delclos, "An environmental management system implementation model for U.S. colleges and universities," Journal of Cleaner Production, vol. 15, no. 7, pp. 660-670, 2007/01/01/2007. https://doi.org/10.1016/j.jclepro.2006.01.013

[14] F. Montabon, S. A. Melnyk, R. Sroufe, and R. J. Calantone, "ISO 14000: assessing its perceived impact on corporate performance," vol. 36, no. 1, pp. 4-16, 2000 https://doi.org/10.1111/j.1745-493x.2000.tb00073.x

[15] M. Potoski and A. Prakash, "Covenants with weak swords: ISO 14001 and facilities' environmental performance," vol. 24, no. 4, pp. 745-769, 2005. https://doi.org/10.1002/pam.20136

[16] K. Aiyub, K. Arifin, A. Awang, and J. M. Jahi, "Environmental performance in Small and Medium sized Enterprises (SMEs) certified to ISO 14001 in the United Kingdom," International Business Management, vol. 3, pp. 7-14, 01/01 2009.

[17] P. Bansal and W. C. Bogner, "Deciding on ISO 14001: Economics, Institutions, and Context," Long Range Planning, Article vol. 35, no. 3, pp. 269-290, 01/01/January 20022002. https://doi.org/10.1016/s0024-6301(02)00046-8

[18] A. Erauskin-Tolosa, E. Zubeltzu-Jaka, I. Heras-Saizarbitoria, and O. Boiral, "ISO 14001, EMAS and environmental performance: A meta-analysis," vol. 29, ed, 2020, pp. 1145-1159. https://doi.org/10.1002/bse.2422

[19] S. A. Melnyk, R. P. Sroufe, and R. Calantone, "Assessing the impact of environmental management systems on corporate and environmental performance," Journal of Operations Management, Article vol. 21, no. 3, pp. 329-351, 01/01/January 2003 2003. https://doi.org/10.1016/s0272-6963(02)00109-2 
[20] F. Testa, F. Rizzi, T. Daddi, N. M. Gusmerotti, M. Frey, and F. Iraldo, "EMAS and ISO 14001: the differences in effectively improving environmental performance," Journal of Cleaner Production, Article vol. 68, pp. 165-173, 04/01/April 2014 2014. https://doi.org/10.1016/j.jclepro.2013.12.061

[21] G. Qi, S. Zeng, X. Li, and C. Tam, "Role of Internalization Process in Defining the Relationship between ISO 14001 Certification and Corporate Environmental Performance," Corporate Social Responsibility \& Environmental Management, Article vol. 19, no. 3, pp. 129-140, 2012. https://doi.org/10.1002/csr.258

[22] I. Heras-Saizarbitoria, G. Arana, and O. Boiral, "Outcomes of Environmental Management Systems: the Role of Motivations and Firms' Characteristics," Business Strategy \& the Environment (John Wiley \& Sons, Inc), Article vol. 25, no. 8, pp. 545-559, 2016. https://doi.org/10.1002/bse.1884

[23] J. Ammenberg, "How do standardised environmental management systems affect environmental performance and business?," Licentiate thesis, comprehensive summary, Linköping Studies in Science and Technology. Thesis, LiU/Unitryck, Linköping, 907, 2001. https://doi.org/10.3384/lic.diva-152878

[24] E. Welch, Y. Mori, and M. Aoyagi, "Voluntary adoption of ISO 14001 in Japan: Mechanisms, stages and effects," Business Strategy and the Environment, vol. 11, pp. 43-62, 01/01 2002. https://doi.org/10.1002/bse.318

[25] T. Zobel, "The impact of ISO 14001 on corporate environmental performance: a study of Swedish manufacturing firms," Journal of Environmental Planning and Management, vol. 59, no. 4, pp. 587-606, 2016/04/02 2016. https://doi.org/10.1080/09640568.2015.1031882

[26] D. Aravind and P. Christmann, "Decoupling of Standard Implementation from Certification: Does Quality of ISO 14001 Implementation Affect Facilities' Environmental Performance?," Business Ethics Quarterly, vol. 21, no. 1, pp. 73-102, 2011. https://doi.org/10.5840/beq20112114

[27] P. Barla, "ISO 14001 certification and environmental performance in Quebec's pulp and paper industry," Journal of Environmental Economics \& Management, Article vol. 53, no. 3, pp. 291-306, 2007. https://doi.org/10.1016/j.jeem.2006.10.004

[28] I. Heras-Saizarbitoria, J. F. Molina-Azorín, and G. P. M. Dick, "ISO 14001 certification and financial performance: selection-effect versus treatment-effect," Journal of Cleaner Production, Article vol. 19, no. 1, pp. 1-12, 01/01/January 2011 2011. https://doi.org/10.1016/j.jclepro.2010.09.002

[29] MEPI, "Measuring the environmental performance of industry," SPRU - Science and Technology Policy Research, University of Sussex6 Dec. 2000 2001, Available: https://www.sustainabilityreports.com/titel-68/.

[30] NDEMS, "National database of environmental management systems," E. L. Institute, Ed., ed. Washington, USA, 2001

[31] A. Gomez and M. A. Rodriguez, "The effect of ISO 14001 certification on toxic emissions: an analysis of industrial facilities in the north of Spain," Journal of Cleaner Production, vol. 19, no. 9, pp. 1091-1095, 2011/06/01/ 2011. https://doi.org/10.1016/j.jclepro.2011.01.012

[32] D. Wathey and M. O'Reilly, ISO 14031: A practical guide to developing environment performance indicators in your business (ISO 14000 environmental series). Norwich, United Kingdom: Stationery Office Books, 2000. https://doi.org/10.1016/s1066-7938(01)00148-8

[33] J. Cohen and J. Cohen, Applied multiple regression/correlation analysis for the behavioral sciences. Mahwah, N.J.: L. Erlbaum Associates, 2003.

[34] T. Oommen, L. G. Baise, and R. M. Vogel, "Sampling Bias and Class Imbalance in Maximum-likelihood Logistic Regression," Mathematical Geosciences, vol. 43, no. 1, pp. 99-120, 2011/01/01 2011. https://doi.org/10.1007/s11004-010-9311-8

[35] V. Bourdès, S. Bonnevay, P. Lisboa, R. Defrance, D. Pérol, S. Chabaud, T. Bachelot, T. Gargi, and S. Négrier, "Comparison of Artificial Neural Network with Logistic Regression as Classification Models for Variable Selection for Prediction of Breast Cancer Patient Outcomes," Advances in Artificial Neural Systems, vol. 2010, p. 309841, 2010/08/23 2010. https://doi.org/10.1155/2010/309841

[36] J. Cohen, Statistical power analysis for the behavioral sciences, 2nd ed. New York: Routledge, 2013, p. 567. [Online]. Available.

[37] S. Holm, "A simple sequentially rejective multiple test procedure," Scandinavian Journal of Statistics, vol. 6, no. 2, pp. 65-70, 1979.

[38] R Core Team, R: A language and environment for statistical computing. R Foundation for Statistical Computing, Vienna, Austria, 2021, URL https://www.R-project.org/

[39] Fox J, Weisberg S, An R Companion to Applied Regression, Third Edition. Sage, Thousand Oaks CA, 2019, https://socialsciences.mcmaster.ca/jfox/Books/Companion/ 
Implementing ISO 14001 and

Environmental Performance Evaluation:

A Logistic Regression Model
S. Alsulamy, I. Falqi, M. Mansour

S. Dawood, A. Alshehri

[40] M. A. A. Mansour, S. D. A. Khadar, and I. I. A. Falqi, "Analyzing the implementation of environmental laws in the Saudi Arabian construction industry," Applied Ecology and Environmental Research, vol. 17, no. 2, pp. 3781-3802, 2019. https://doi.org/10.15666/aeer/1702_37813802

[41] ISO_survey_2018.(2018, 20 Jan. 2019). ISO suvey 2018 results - number of sectors by country for each standard. Available: https://isotc.iso.org/

[42] S. M. Ravitch and N. M. Carl, Qualitative research: bridging the conceptual, theoretical, and methodological. Los Angeles: SAGE, 2016, p. 567.

[43] M. Ingo and R. Klinkenberg, "RapidMiner Studio 9.5.001," rev: 24d768 ed: RapidMiner, Inc., 2019.

[44] V. Kotu and B. Deshpande, "Chapter 3 - data exploration," in Predictive Analytics and Data Mining, V. Kotu and B. Deshpande, Eds. Boston: Morgan Kaufmann, 2015, pp. 37-61. https://doi.org/10.1016/b9780-12-801460-8.00003-3

[45] International Organization for Standardization, Environmental management - environmental performance evaluation - guidelines (ISO 14031:2013).Geneva, Switzerland. https://www.iso.org/standard/52297.html

[46] B. L. Simula, "Book review: the coding manual for qualitative researchers, 3rd ed," vol. 46, no. 2, pp. 173-175, 2018. https://doi.org/10.1177/0092055x18760362

[47] D. Wicks, The coding manual for qualitative researchers (Qualitative Research in Organizations and Management: An International Journal). Johnny Saldaña Sage 2017, pp. 169-170. https://doi.org/10.1108/qrom-08-2016-1408

[48] S. W. Menard, Handbook of longitudinal research: design, measurement, and analysis. Amsterdam; Boston: Elsevier, 2008.

[49] J. Louviere, D. Hensher, and J. Swait, Stated choice methods: analysis and application. Cambridge University Press, 2000.

[50] S. B. Merriam and E. J. Tisdell, Qualitative research: a guide to design and implementation, 4 ed. (JosseyBass higher and adult education series). San Francisco, CA: Jossey-Bass: A Wiley Brand, 2016, p. 346. https://doi.org/10.5860/crl.66.1.74

Submitted: $\quad 22.4 .2020$

Accepted: $\quad 27.8 .2021$
Saleh Alsulamy

Architecture and Planning Engineering

Department, College of Engineering, King Khalid University, Abha 394, Saudi Arabia; s.alsulamy@kku.edu.sa Ibrahim Falqi Civil Engineering Department, College of Engineering, King Khalid University, Abha 394, Saudi Arabia; ifalqi@kku.edu.sa

Mohamed Mansour ${ }^{*}$ Industrial Engineering Department, College of Engineering, Zagazig University, 44519 Zagazig, Egypt Industrial Engineering Department, College of Engineering, King Khalid University, Abha 394, Saudi Arabia Shaik Dawood Industrial Engineering Department, College of Engineering, King Khalid University, Abha 394, Saudi Arabia

Abdullah Alshehri

Civil and Environmental Engineering Department, College of Engineering, Majmaah University, Majmaah 11952, Saudi Arabia; a.m.alshehri@mu.edu.sa *Corresponding author: momansor@kku.edu.sa 